\title{
Is less-than-full-time training in dentistry swimming against the tide?
}

\author{
Sami Stagnell, ${ }^{* 1}$ Nikki Patel ${ }^{2}$ and Sam Shah ${ }^{3}$
}

\section{Key points}

\begin{abstract}
With ongoing changes to the demography of the dental workforce coupled with the changing expectations of those participating in early career post-graduate training, dentistry is experiencing a shift in how it might manage trainees. Drawing on experience from medicine and the anticipated behavioural differences, it is worth considering a way in which training might be able to adapt to the requirements of newer graduates, to ensure that the profession does not lose out on preparing the best candidates possible for careers that improve the state of dentistry both as a vocation and for patient benefit.
\end{abstract}

\section{Introduction}

As the dental landscape continues to evolve via the manifestation of changes to commissioning, workforce and skillsets, it is certain that the impact of how we see dentistry and the way the public access it will be profound. It has been suggested in the last few years that the demographic of students entering dental training has changed dramatically; inevitably, this has the potential to change where and how dentists work in the future as the new generation of trainees coming through have a different mindset to their predecessors. When this is combined with modifications to how patients are managed, in the context of how the new commissioning guides suggest patient-flow might be affected, it is obvious that big changes are afoot.

In recognising the changing tide, it is prudent to consider how the profession might adapt to best accommodate themselves in times of uncertainty. This includes how

${ }^{1}$ Specialist Oral Surgeon, 30 Ashley Road, Boscombe, UK; ${ }^{2}$ Dentist and Clinical Lead, Digital Development, NHS England, London, UK; ${ }^{3}$ Specialist in Dental Public Health Honourary Lecturer, University of Kent, London, UK.

${ }^{\star}$ Correspondence to: Sami Stagnell

Email: sstagnell@nhs.net

Accepted 28 May 2019

https://doi.org10.1038/s41415-019-0676-x we facilitate further training and also how specialists across primary and secondary care manage themselves in the workplace to best position themselves and their colleagues to accommodate their lifestyle and career needs.

Inevitably, the future workforce will have different requirements and now is the time to decide how to meet its needs. Additionally, specialist training numbers and services delivered by specialists and consultants (level 3 services) will need to reflect the needs of the population and the changing demographics of local areas. With this concept in mind, one option that currently exists within training frameworks stands out as one potential solution. Despite the paucity in data available reflecting different areas of workforce across in dentistry, integration and adaptation of lessthan-full-time training (LTFT) are explored here, as a more common means of training might resolve some of the uncertainties that exist around the developing workforce.

\section{Health Education England dental workforce group}

Health Education England (HEE) has established a 'dental workforce group' which aims to collect data on the need for speciality training posts in the 13 recognised dental specialties to create a dental workforce strategy to meet population needs. ${ }^{1}$ The group recently made recommendations which included: ' [we] need to liberate the workforce to facilitate the necessary developments and continue to shape it over time to serve population needs, ${ }^{2}$ and that 'this requires courage, creativity and collaboration to move our workforce from good to great'.

Demand for the development of specialists will also be determined by the needs of the local population and advice around development should be sought from dental public health groups as well as commissioners and providers of service. The commissioning guides which continued to evolve in 2015 are likely to 'result in new models of dental care delivery over time; and the need for much closer working between HEE and NHS England at both national and LETB level to ensure both current and future dental workforce development needs can be met.'

\section{Current specialist trainees}

When considering the speciality workforce, we must consider how speciality training exists in its current context; this article does not aim to replicate articles that have previously been produced but only purvey an overview. ${ }^{3}$ There are currently 13 routes onto specialist lists that are recognised by the General Dental Council (GDC). ${ }^{4}$ The number of trainees that currently exist in training varies between 
specialties (Fig. 1), as well as geographically (Fig. 2).5,6 The routes to speciality status are also varied and are explicitly detailed by the Committee of Postgraduate Dental Deans and Directors (COPDEND).?

Beyond speciality training, there is also much work and debate around level 2 dentists and their role in intermediate services. Ibbetson remarked that, in the void between primary and secondary dental care, where the intermediate services have been evolving, is a distinct lack of development surrounding this type of competency that is not addressed by specialists given a potential lack of funding within the health service. ${ }^{4} \mathrm{He}$ suggests that this lack of funding and development of the middle tier has given rise to a stagnation of any progress that may encourage more dentists to progress with their own careers and skills. Responses to this opinion piece highlighted that, in the case of oral surgery, the need for specialists and consultants is perhaps dictated by the commissioning guidelines in their call for dispensation of services to appropriatelytrained clinicians. The subsequent development of services such as oral surgery has seen the evolution of accreditation criteria ${ }^{8}$ for those in such services, but has drawn equal criticism regarding the effects of such guidelines and in consideration of other aspects of workforce development. ${ }^{9}$

\section{Less-than-full-time training (LTFT)}

\section{What is LTFT training?}

LTFT training is defined by European Law (EC directive 93/16/EEC) as being part-time training that involves a limitation in participation in medical or dental activities, but trainees must usually work at least half the time of a full-time trainee. The Dental Gold Guide 2016 outlines the parameters in which an individual can apply for LTFT training. ${ }^{10}$ All trainees are entitled to apply for LTFT training, provided they meet eligibility criteria which include illness, disability, caring responsibilities, and opportunities for personal and professional development. The guide states only one additional reason why LTFT training may be considered: 'if the supply/demand ratio of potential trainees is unfavourable then HEE, NES, NIMDTA or Wales Deanery may consider the development of part-time training posts in specific specialties. It is within this context that it may be worth considering how training the workforce might be adapted to best fit changes

Fig. 1 Dentists in specialist training posts at 31 December $2013^{43}$

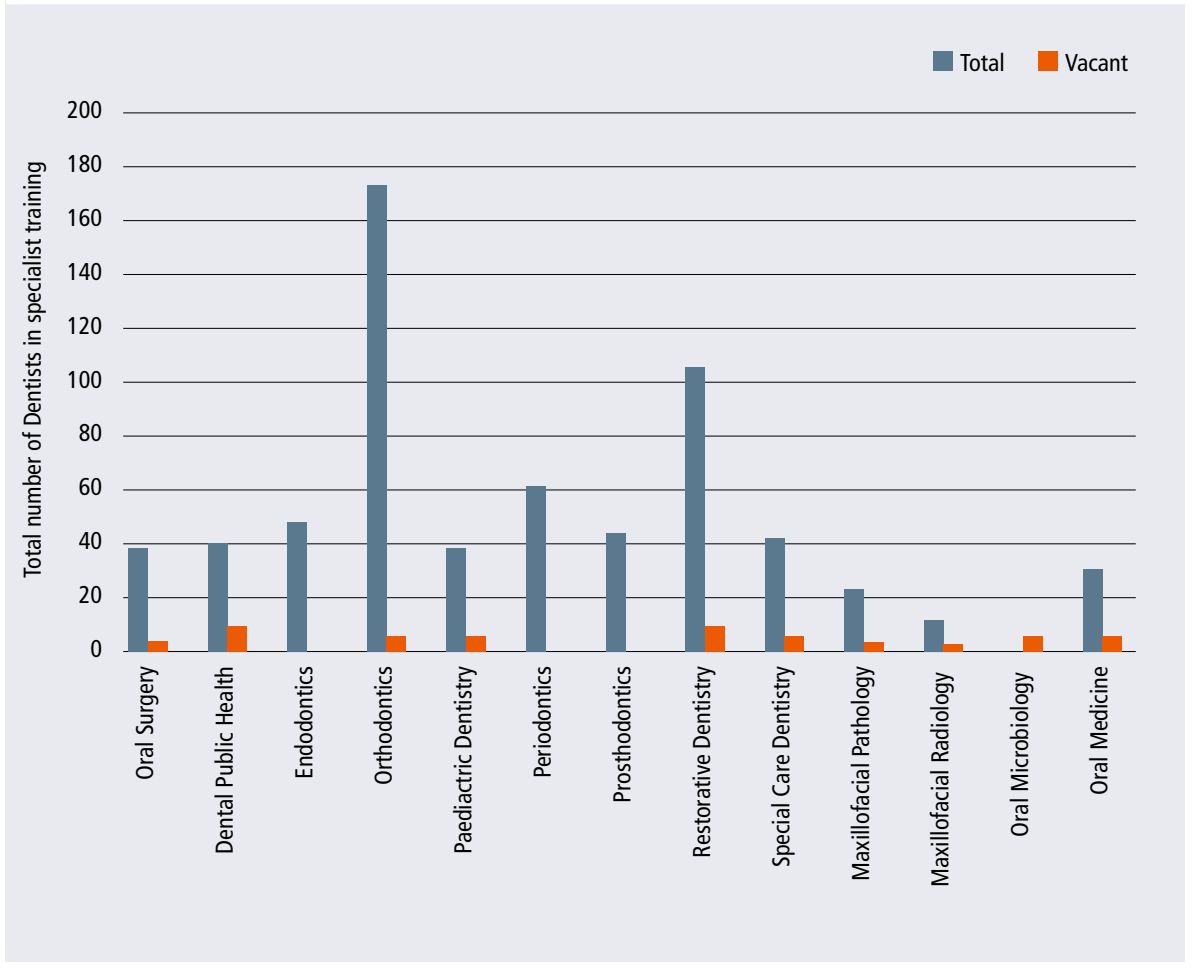

in the profession. LTFT is traditionally a facilitator that can help dental professionals to stay in the profession who otherwise may have been lost from the workforce if they are unable to commit full-time to a post for a variety of reasons.

Identifying data pertaining to dentistry is challenging with respect to how many LTFT trainees are currently in post and the historical trends. However, it seems there are only few when discussing with educators; full consideration of this data would aid workforce planning teams to evaluate the projected need for specialists in the future more accurately alongside the changing expectations of those undergoing training.

Here we outline possible reasons why some dental professionals may want to consider LTFT to become level 3 practitioners and why considering this in the development of future posts may be of benefit to the profession.

\section{Comparisons to medicine}

NHS medical and dental staff are bound by the same terms and conditions of service. ${ }^{11}$ The General Medical Council's 'National training survey 2014' shows that $11.3 \%$ of doctors were in LTFT training, up from $6.1 \%$ in $2011 .{ }^{12}$ The 'Shape of training' review recommended that future training models should be more flexible, to achieve a better work-life balance, pursue outside interests or research, teaching, or leadership responsibilities. ${ }^{13}$ This was then championed by the BMA, GMC, ${ }^{14}$ medical Royal Colleges and other national organisations to build a diverse and sustainable workforce. A study by Hunningher et al. found that LTFT anaesthetic trainees (95.6\%) were as successful as full-time trainees $(95.7 \%)$ at obtaining consultant jobs. ${ }^{15}$ The BMA currently offers guidance, ${ }^{16}$ as well as detailed figures, ${ }^{17}$ for trainees considering and currently in LTFT placements.

There is currently a lack of evidence showing the training outcomes of LTFT dental speciality trainees: If dental trainees are bound by the same terms and conditions, it could be argued that we should be supporting more opportunities based on existing evidence. ${ }^{18}$

\section{Lifestyle and morale}

Working LTFT has many benefits, including reducing exhaustion, preventing burnout and achieving a better work-life balance, which can in turn improve enthusiasm for work. Several studies have reported that young trainees often struggle with morale ${ }^{19}$ and one of the many reasons for choosing a career within dentistry is typically an association with quality of life within the profession as well as flexibility in working life. ${ }^{20,21}$ Furthermore, feeling a sense of value as well as being able to maintain personal values and aspirations 
Fig. 2 Speciality training posts at 31 December 2013, by HEE area in UK

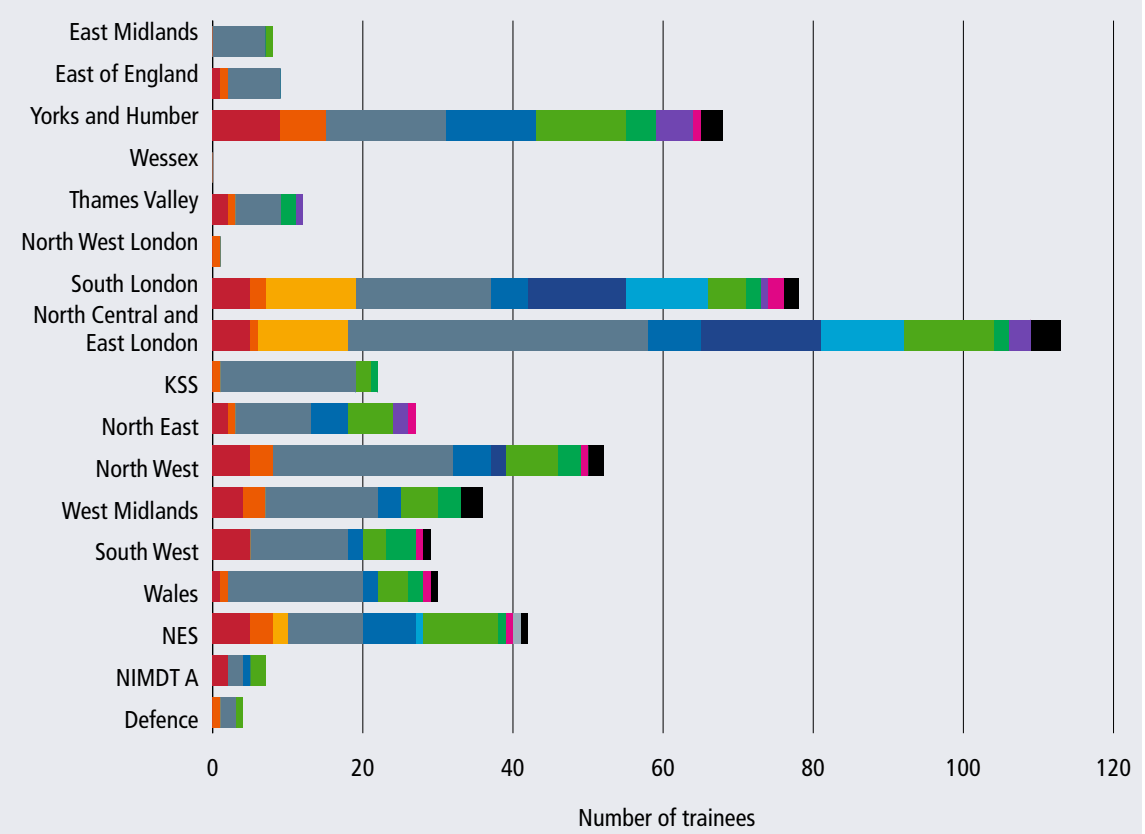

\begin{tabular}{|c|c|c|c|}
\hline Oral Surgery & Dental Public Health & Endodontics & Orthodontics $\square$ Paediactric Dentistry \\
\hline Periodontics & Prosthodontics & Restorative Dentistry & Special Care Dentistry \\
\hline Maxillofacial Pathology & Maxillofacial Radiology & Oral Microbiology & Oral Medicine \\
\hline
\end{tabular}

as part of career progression appears to be important. ${ }^{22,23}$ Although underreported, there are studies highlighting how burnout within the profession is not an unknown ailment affiliated with several career stresses; ${ }^{24,25}$ some investigations have shown up to $75 \%$ of those in training (depending on speciality) may suffer from burnout. ${ }^{26}$ The British Dental Association has highlighted that there is strong evidence that working under the current NHS contract is associated with stress and burnout among dentists. ${ }^{27}$

\section{Gender equality}

It has been determined that healthcare professionals are increasingly seeking flexible solutions within their working lives to enable them to achieve their potential in their careers but also to be able to properly support their families.

It is clearly apparent that females are more likely than males to take time off work and subsequently work part-time following the birth of a child, ${ }^{28}$ and this is also apparent based on figures from the $\mathrm{BMA}^{17}$ The number of women working in NHS dentistry is steadily rising. In $2014 / 15$, there was a $3.1 \%$ increase in the number of female dentists from 2013/14 in England. ${ }^{29}$ This equates to a $44.2 \%$ increase from $2006 / 07$. With the changing demographics of an increase in female dentists coupled with the fact they are currently more likely to work part-time, there needs to be an overhaul in future workforce planning. However, the introduction of shared parental leave in 2015 may stimulate cultural changes to fade out typical gender roles, which may start to erode the current demographics. ${ }^{30}$

Either way, there will be an increasing need for flexibility in training for dentists wishing to progress their careers to provide a level 3 service. If the recently published commissioning guides suggest more level 3 services are required than are currently in the dental market, consideration will need to be given to flexible working and training in order to meet the workforce requirements for the future of the dental profession. Additionally, it could be argued that, by limiting the provision of LTFT, it could be deemed as gender discrimination against females who wish to work or train part-time. Newton suggested 'if we wish to retain the rich diversity and quality of dental practitioners that we now have then we may need to think about structuring employment to make it easier for those who choose to work part-time. ${ }^{31}$

\section{Finance}

Some dental speciality training posts are accompanied with high course fees, including orthodontics and mono-speciality courses for endodontics, periodontics and prosthodontics. During the training period, a stipend may or may not be available. Those courses where one is available, the pay scale is usually that for NHS speciality registrars. Those dental professionals who do not have the financial means to accept a limited income, or no income at all, may seek to train LTFT to supplement their income by working elsewhere for the remainder of the week, for example in general dental practice. Not considering LTFT training for level 3 services will create inequalities and inequities within the dental workforce. This can be viewed as the process being anti-competitive due to the constraints on the learning and development of the dental workforce and act as a barrier for well able and qualified potential candidates from applying for speciality training posts.

\section{Disability and carers}

Some dental professionals may have a disability or medical condition of some form, which may prevent them from working full-time in a post. The BMA estimate that $2.5 \%$ of LTFT training posts in medicine are owing to a disability. ${ }^{32}$ Not allowing the consideration of LTFT posts to gain specialist skills may potentially be seen as discrimination. Additionally, some professionals may have responsibilities as carers for close family. By having the option of LTFT, the dental workforce can take advantage of highly-skilled potential candidates who otherwise would not be able to progress in their careers.

\section{The 'portfolio' career}

As dentistry becomes more competitive in terms of the service we provide and tendering of contracts, there seems to be an aspiration towards the development of the 'portfolio career.' Portfolio careers offer more flexibility, variety, autonomy, freedom and a better work-life balance, as well as risk tolerance. It enables an individual to use multiple skill sets and allows them to follow multiple passions for personal growth and fulfilment. Although a new concept to some in terms of the title, many are already inadvertently pursuing such careers through the sheer diversity of their working week (for example, combining clinical work with teaching, academia, supporting other business interests etc). Furthermore, a 
study of academic clinical fellows (academic speciality trainees) showed that most would not pursue isolated research/academic careers because of competition around securing grants and internal job pressures. ${ }^{33}$ These multifaceted elements have been highlighted in dental circles too. ${ }^{34}$ Due to the lack of job security in today's workplace, it would be wise to consider multiple facets, especially within the dental profession.

There are currently few incentives to incorporate a career in academia with clinical practice in dentistry. The development of NIHR-funded academic clinical fellowship (ACF) posts have helped to alleviate this in recent years. ${ }^{35}$ However, limiting the availability of LTFT posts may further discourage dentists with an interest in academia from pursuing this alongside their specialist training.

It has never been more critical to gain training in management and leadership within dentistry, in order to keep abreast of the ever-changing health care system and to prepare specialists for roles in teaching, education and department management. To accommodate this requirement, LTFT can assist in professional development and gaining competency in this area.

With the changing mindset of trainees and practitioners hinting towards a more varied and diverse career, it is essential that training reflects this change in behaviour so as not to upset health services and workforce balance: ${ }^{15}$ this is also crucial if the public health sector wants to retain trainees in the service as well as support a more formalised structure to empower training in this way.

Will we be moving towards a model where specialists only work part-time delivering level 3 services and spend the remainder of their working week working in specialist primary care? If more specialists are needed in line with the requirements in the commissioning guides and more are working part-time in NHS, this might create more variety in the workforce resulting in a wider array of competencies and ways of thinking, which could bring an increased innovative and creative mix to the profession.

\section{Impact on the specialist workforce}

Consideration should be given to the likelihood of LTFT trainees taking up LTFT consultant posts upon completion of training. Hunningher et al. ${ }^{15}$ found that only $3.4 \%$ of LTFT anaesthetic trainees took up LTFT consultant posts, compared to $1.75 \%$ full-time trainees $^{36}$ taking up LTFT consultant posts. Seemingly, this has only a small impact on whole time equivalent consultant numbers.

If there are an increasing number of individuals who wish to work in consultant posts as LTFT, there may need to be a shift in the consultant workforce structure and how we delegate working time equivalents. This could be deemed advantageous by having more consultants in the workforce who may bring varied ideas and innovations to further benefit patients and the workforce as a whole. The concept of job sharing is not new, ${ }^{37}$ however the influence on job role and speciality has previously been seen to affect who is more likely to take on less-than-full-time job roles. ${ }^{38}$ Irrespective of this, work-life balance has been seen to clearly influence early career choices in medical trainees. . $^{39,40}$

\section{Challenges for LTFT}

A direct effect of LTFT is that take-home pay will be reduced on a pro-rata basis and pay progression will take longer. Conversely, the opportunity to support oneself in general practice as a dentist provides an opportunity to supplement income (in a way not often available to those in medicine) and for certain specialties, such as dental public health, this may provide an opportunity to engage with clinical activity too, especially as completion of training is delayed.

Those working in LTFT posts have reported they feel they are taken less seriously than their full-time colleagues. ${ }^{41}$ It can also be difficult to attend training sessions if they fall on a non-working day of the week. Demonstrating commitment through working longer hours may also prove more challenging. The lack of continuity may be a major drawback of working LTFT, not only in terms of patient care, but also in terms of learning and acquiring a breadth of experience.

Funding for LTFT posts may prove challenging for NHS trusts and education commissioners, that is, HEE. Individuals may work in a 'job share' or a 'slot share' with other colleagues wishing to work or train LTFT, or may be a supernumerary, finance-permitting, and might require pilot-type programmes to support their validity.

Other challenges may include:

- Training will take longer to complete, meaning a longer wait until more specialists are in circulation
- It may take longer to become integrated with the team

- Training opportunities may be missed or limited

- Less continuity with patients (workload/ speciality specific).

To prevent these challenges from occurring, it is vital that professionals wishing to train LTFT for level 3 service provision ensure they fulfil all the competencies required to the minimum standards expected of the GDC for completion of specialist training. ${ }^{42}$

\section{Conclusion}

The case for LTFT appears to remain strong, however the model of training delivery may need to evolve to maintain pace with the changing service delivery model in the NHS. The range of training opportunities may also need to be broadened to meet the wider requirements of the health system. Flexibility within LTFT seems to be a valid consideration and should be factored in to support portfolio careers and to optimise the opportunities open to trainees. The model of LTFT training managed by HEE can appear inconsistent when applied to dentistry and does not necessarily recognise the specific needs of dentistry. The dental workforce needs are likely to change again and, as such, LTFT training needs to be developed to meet these needs.

\section{References}

1. Health Education England. Future oral and dental workforce for England. 2016. Available at https:// www.hee.nhs.uk/our-work/advancing-dental-care/ future-oral-dental-workforce-england (accessed August 2019).

2. Health Education England. The Future Oral and Dental Workforce for England. 2019. Available at https:// www.hee.nhs.uk/sites/default/files/documents/ FDWF\%20Report\%20-\%207th\%20March\%202019. pdf (accessed August 2019).

3. Critchlow $S$, Nanayakkara L. A guide to entry into specialist training. Br Dent J 2012; 212: 35-40.

4. General Dental Council. Specialist lists. Available at https://www.gdc-uk.org/professionals/specialist-lists (accessed August 2019).

5. Ibbetson R. Postgraduate training in dentistry. Fac Dent J 2015; 4: 168-171.

6. Specialty Training Posts Summary' COPDEND 2013.

7. COPDEND. Dental Gold Guide 2018. Available at https://www.copdend.org/downloads-list/dentalgold-guide-2018/ (accessed August 2019).

8. LDC Confederation. Accreditation documents for NHS "level 2" dental providers and performers released. 2017. Available at https://ldc.org.uk/accreditationdocuments-for-nhs-level-2-dental-providers-andperformers-released/ (accessed August 2019).

9. $D^{\prime} C r u z L$. Tier 2 NHS services in primary dental care where are the risks? Br Dent J 2018; 224: 927-929.

10. COPDEND. Dental Gold Guide 2018: A guide to postgraduate specialty training in the UK. 2018. Available at https: //www.copdend.org/downloadslist/dental-gold-guide-2018/ (accessed August 2019). 
11. NHS Employers. Terms and Conditions of Service NHS Medical and Dental Staff (England). 2002. Available at https://www.nhsemployers.org/ /media/Employers/ Documents/Pay\%20and\%20reward/Terms_and_ Conditions_of_Service_NHS_Medical_and_Dental Staff 300813 bt.pdf (accessed August 2019).

12. General Medical Council. National training survey 2014. Available at https://www.gmc-uk.org/-/media/ documents/NTS_2014_KFR_A4.pdf_56706809.pdf (accessed August 2019).

13. Greenaway D. Securing the future of excellent patient care: final report of the independent review. Shape of Training review. 2013. Available at https://www. shapeoftraining.co.uk/static/documents/content/ Shape_of_training_FINAL_Report.pdf_53977887.pdf (accessed August 2019).

14. General Medical Council. Less than full time training. Available at https://www.gmc-uk.org/education/ standards-guidance-and-curricula/positionstatements/less-than-full-time-training (accessed August 2019).

15. Hunningher A, Young T E, Johnston C. Evaluation of less than full-time training in anaesthesia: a national survey. 2010.

16. British Medical Association. Flexible working and LTFT. Available at https://www.bma.org.uk/advice/ career/applying-for-training/flexible-training-and-ltft (accessed August 2019).

17. British Medical Association. Less than full time guidance. 2015. Available at https://www. gmc-uk.org/-/media/documents/NTS_2014_KFR_ A4.pdf_56706809.pdf (accessed August 2019).

18. Cleland J, Johnston P, Watson V Krucien D, Skåtun D. What do UK doctors in training value in a post? A discrete choice experiment: Med Educ 2016; 50: 189-202.

19. Lambert T, Smith F, Goldacre M J. Doctors' views about their work, education and training three years after graduation in the UK: questionnaire survey. JRSM Open 2015; 6: DOI: 10.1177/2054270415616309.

20. Gallagher J E, Clarke W, Wilson N H. Understanding the motivation: a qualitative study of dental students' choice of professional career. Eur J Dent Educ 2008; 12: 89-98.
21. Wilson N H, Clarke W, Eaton K A, Gallagher J E. Vocational dental practitioners' choice of professional career: a qualitative study, in IADR. 2007.

22. Gallagher J E, Clarke W, Eaton K A, Wilson N H. A question of value: a qualitative study of vocational dental practitioners' views on oral healthcare systems and their future careers. Prim Dent Care 2009; 16: 29-37.

23. Newton $\mathrm{P}$, Cabot L, Wilson N H, Gallagher J E. The graduate entry generation: a qualitative study exploring the factors influencing the career expectations and aspirations of a graduating cohort of graduate entry dental students in one London institution. BMC Oral Health 2011; 11: 25.

24. Vered Y, Zaken Y, Ovadia-Gonen H, Mann J, Zini A. Professional burnout: Its relevance and implications for the general dental community. Quintessence Int 2014; 45: 87-90

25. Newton J T, Allen C D, Coates J, Turner A, Prior J. How to reduce the stress of general dental practice: the need for research into the effectiveness of multifaceted interventions. Br Dent J 2006; 200: 437-440.

26. Ishak W W, Lederer S, Mandili C et al. Burnout during residency training: a literature review. J Grad Med Educ 2009: 1: 236-242.

27. Larbie J, Kemp M, Whitehead P. The mental health and well-being of UK dentists: a qualitative study. London: British Dental Association, 2017.

28. Robinson P G, Patrick A, Newton T. Modelling the dental workforce supply in England. Sheffield: University of Sheffield, 2011.

29. NHS Dental Statistics. NHS Dental Statistics for England - 2014/15. Available at https://digital.nhs. uk/data-and-information/publications/statistical/ nhs-dental-statistics/nhs-dental-statistics-forengland-2014-15 (accessed August 2019).

30. ACAS. Shared parental leave and pay. Available at http://www.acas.org.uk/index.aspx?articleid $=4911$ (accessed August 2019).

31. Newton J T, Buck D, Gibbons D E. Workforce planning in dentistry: the impact of shorter and more varied career patterns. Community Dent Health 2001; 18: 236-241.

32. British Medical Association. Less-than full-time training guidance update. 2018. Available at https:// www.bma.org.uk/news/2015/august/less-than-fulltime-training-guidance-update (accessed August 2019).

33. Goldacre M J, Lambert T W, Goldacre R, Hoang U. Career plans and views of trainees in the Academic Clinical Fellowship Programme in England. Med Teach 2011; 33: e637-e643.

34. Whitehouse L. Dental academics: our future dental academics. Br Dent J 2019; 226: 162.

35. NIHR. Integrated Academic Training. Available at https://www.nihr.ac.uk/explore-nihr/academyprogrammes/integrated-academic-training.htm (accessed August 2019).

36. Eyre H A, Mitchell R D, Milford W, Vaswani N, Moylan S. Portfolio careers for medical graduates: implications for postgraduate training and workforce planning: Aust Health Rev 2014; 38: 246-251.

37. Thornicroft $G$, Strathdee $G$. Job share a consultant post. BMJ 1992; 305: 1413-1415.

38. Lachish S, Svirko E, Goldacre M J, Lambert T. Factors associated with lessthanfull-time working in medical practice: results of surveys of five cohorts of UK doctors, 10 years after graduation. Hum Resour Health 2016; 14: 62

39. Smith F, Lambert T W, Goldacre M J. Factors influencing junior doctors' choices of future specialty: trends over time and demographics based on results from UK national surveys. JR Soc Med 2015; 108: 396-405.

40. Spooner S, Pearson E, Gibson J, Checkland K. How do workplaces, working practices and colleagues affect UK doctors' career decisions? A qualitative study of junior doctors' career decision making in the UK. BMJ Open 2017; 7: e018462.

41. Medical Women's Federation. Less than full time training (LTFT). Available at http://www. medicalwomensfederation.org.uk/advice-support/lessthan-full-time-training\#faq (accessed August 2019).

42. General Dental Council. Standards for specialty education: standards and requirements for providers. 2015. Available at https://www.gdc-uk.org/api/ files/Standards $\% 20$ for $\% 20$ Education $\% 20$ (v2 $\% 20$ revised\%202015).pdf (accessed August 2019).

43. Ibbetson R. Postgraduate training in dentistry. Fac Dent J 2015 6: 168-171. 